\title{
Human adipose tissue-derived stem cells in breast reconstruction following surgery for cancer: A controversial issue
}

\author{
Maria Giovanna Scioli ${ }^{1}$, Valerio Cervelli ${ }^{2}$, Pietro Gentile ${ }^{2}$, Alessandra Bielli $^{1}$, Roberto Bellini ${ }^{1}$, \\ Augusto Orlandi ${ }^{*}$ \\ ${ }^{1}$ Anatomic Pathology, Department of Biomedicine and Prevention, Tor Vergata University, Rome, Italy; \\ *Corresponding Author: orlandi@uniroma2.it \\ ${ }^{2}$ Plastic Surgery, Department of Biomedicine and Prevention, Tor Vergata University, Rome, Italy
}

Received 6 November 2012; revised 17 January 2013; accepted 17 February 2013

Copyright (C) 2013 Maria Giovanna Scioli et al. This is an open access article distributed under the Creative Commons Attribution License, which permits unrestricted use, distribution, and reproduction in any medium, provided the original work is properly cited.

\begin{abstract}
Breast cancer is the most common cancer in women. Patients, in particular young women, after surgical removal of the tumor have a poorer quality of life and psychological problems. Plastic surgery procedures for breast reconstruction, including autologous fat grafting, concur to reduce cosmetic and psychological problems. The maintenance of the transplanted fat is partially due to the presence of resident adipose derived-stem cells (ASCs). The latter can be isolated by digestion and centrifugation from the stromal vascular fraction (SVF) of subcutaneous adipose tissue. Intraoperatory SVFIASC enrichment has been proposed to stabilize and optimalize autologous fat engraftment for breast reconstructive surgery after mastectomy, but the safety of these procedures is still uncertain. Although the literature offers contrasting opinions concerning the effects of ASCs on cancer growth according to the tumor type, at the present time ASC implementation for regenerative medicine therapies should be carefully considered in patients previously treated for breast cancer. At the present, reconstructive therapy utilizing ASCenriched fat grafting should be postponed until there is no evidence of active disease.
\end{abstract}

Keywords: Human Adipose-Derived Stem Cells; Breast Cancer; Breast Reconstruction; Fat Grafting

\section{INTRODUCTION}

Breast cancer is the most common cancer in women.
Patients, in particular young women, after surgical removal of the tumor have a poorer quality of life and psychological problems. The use of lumpectomy and adjuvant radiation as surgical approach has contributed to ameliorate cosmetic and functional outcomes. In addition, ameliorated plastic surgery procedures for breast reconstruction, including autologous fat grafting [1], concur to reduce cosmetic and psychological problems. The maintenance of the transplanted fat is partially due to the presence of adipose derived-stem cells (ASCs). The latter can be isolated from the stromal vascular fraction $(\mathrm{SVF})$ after digestion and centrifugation of residual subcutaneous adipose tissue [2]. ASCs maintain the expression of stem cell markers in vitro (Figure 1). Preliminary reports describe the increased efficacy of autologous fat grafting when associated to SVF enrichment for regenerative surgery purposes [3]. ASCs represent a good model to address questions concerning specific differentiation strategies. ASCs are readily responsive to platelet-derived growth factors and insulin $[4,5]$. The plasticity of human ASCs offers a stimulating potential in regenerative medicine and surgery [6]. However, a critical review of the literature reveals considerable uncertainty. In particular, the differentiation of ASCs into cell lineages apart from adipocytes has not been conclusively demonstrated in many studies due to the use of rather simplistic approaches, nonspecific histological confirmation, or a small number of specific markers. ASCs have been proposed to stabilize autologous fat grafts for regenerative therapy, but their safety is unknown in the setting of reconstructive surgery after mastectomy. Nevertheless, the full clinical potential of ASCs awaits much deeper investigation. In this sense, it must be clearly evaluated if enrichment with SVF of autologous engrafted fat tissue could be considered a safe pro- 

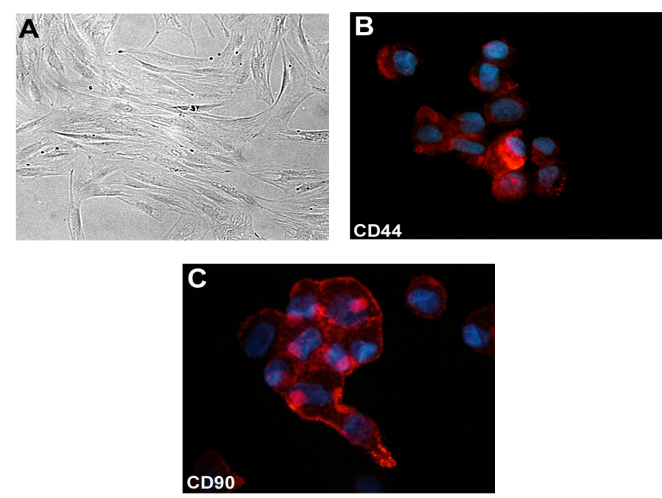

Figure 1. (A) Phase contrast micrograph of ASCs cultured in the presence of $10 \%$ FBS. Original magnification 200×. (B)-(C) Immunofluorescent staining for CD44 and CD90 stromal stem cell markers of cultured ASCs. Original magnification, (A): 200×; (B): $600 \times$.

cedure for all patients undergoing breast reconstruction following traditional surgery or new combined therapies for small breast cancers [7].

\section{ADIPOSE DERIVED STEM CELLS AND BREAST RECONSTRUCTION}

Whilst there has been no direct evidence linking fat grafting in the breast to an increased risk of cancer progression, recent scientific attention has turned to whether the transfer of ASCs-containing SVF could favour an increased risk of breast cancer development or recurrence [6]. The first evidence of interplay between adipose tissue and cancer cells was reported by Manabe et al. [8]; they demonstrated that rat mature adipocytes and preadipocytes stimulated proliferation of oestrogen receptor positive breast cancer cell lines in 3D collagen matrices [8]. Successive studies confirmed that ASCs increased proliferation and invasive potential of breast cancer cells $[9,10]$. Human ASCs co-cultured with MCF7 breast cancer cells secreted transforming growth factor- $\beta 1$ and regulated the establishment of extracellular matrix [11]. These findings suggest that ASCs may promote cancer diffusion by stimulating the extracellular matrix assembly process. As concerning the role of ASCs in non-breast cancer progression, data are contradictory. Findings similar to those obtained with breast cancer cells were documented with osteosarcoma cells with or without murine mesenchymal stem cells [12]. Opposite conclusions have been made for prostate cancer. ASCs were found to be nontumorigenic and capable to variably reduce tumor growth and prostate tumor establishment in two prostate cancer xenograft models in vivo, as well using a soft agar assay in vitro [13]. Recent studies indicate that soluble factors from breast cancer cells inhibit adipogenic differentiation while increase prolif- eration, pro-angiogenic factor secretion, and myofibroblastic differentiation of ASCs [14]. Extracellular matrix deposition increased stiffness and, in turn, facilitated changes in ASC behaviour [14]. The potential concern of autologous fat transfer is that enrichment with ASCs may contribute to stromal support for cancer cells and to deliver locally inflammatory cytokines and/or growth factors, thus facilitating potential residual cancer cell survival and growth. Recent data suggest that a small subpopulation of cancer stem cells is responsible for tumor dedifferentiation, metastasis and chemotherapy resistance. Moreover, malignant cells can reprogram and de-differentiate, so acquiring a stemness phenotype. Inflammatory signals, such as TGF- $\beta$, TNF- $\alpha$, and NF- $\mathrm{kB}$, induce the expression of specific molecules. Transglutaminase 2 , is an extracellular matrix molecule that plays a relevant role in TGF- $\beta$-driven osteocartilagineous tissue remodeling [15]. Transglutaminase 2 has been recently recognized to drive the ovarian tumor cell phenotypic conversion sustaining the epithelial-mesenchymal transition and stemness appearance [16]. A potentially less stable population of engrafted mesenchymal stem cells likely contribute to inflammatory/growth factor-driven residual breast cancer growth, so representing an undetermined or too high potential risk compared to the aesthetic advantage [17]. Nevertheless, in an interesting study, Zimmerlin et al. [18] tested tumorigenesis of tumor cells from metastatic pleural effusion from breast cancer patients in ASC co-cultures. The Authors provided convincing evidence that ASCs enhanced the growth of active, but not resting tumor cells and concluded that reconstructive therapy utilizing ASC-augmented whole fat should be postponed until there is no evidence of active disease [18].

\section{CONCLUSION}

Current scientific evidence suggests that ASC implementation for regenerative medicine therapies should be carefully considered in patients previously treated for breast cancer. Reconstructive therapy utilizing SVF/ASCenriched fat grafting should be postponed until there is convincing clinical and anamnestic evidence of absence of active disease.

\section{ACKNOWLEDGEMENTS}

We thank Ms S. Cappelli for technical assistance. This work was partially supported by a 2012 grant from Transplantation Agency of Lazio, Rome, Italy.

\section{REFERENCES}

[1] Missana, M.C., Laurent, I., Barreau, L. and Balleyguier, 
C. (2007) Autologous fat transfer in reconstructive breast surgery: Indications, technique and results. European Journal of Surgical Oncology, 33, 685-690. doi:10.1080/028418501127346846

[2] Mitchell, J.B., McIntosh, K., Zvonic, S., Garrett, S., Floyd, Z.E., Kloster, A., Di Halvorsen, Y., Storms, R.W., Goh, B., Kilroy, G., Wu, X. and Gimble, J.M. (2006) Immunophenotype of human adipose-derived cells: Temporal changes in stromal-associated and stem cell-associated markers. Stem Cells, 24, 376-385. doi:10.1634/stemcells.2005-0234

[3] Cervelli, V., Gentile, P., De Angelis, B., Calabrese, C., Di Stefani, A., Scioli, M.G., Curcio, B.C., Felici, M. and Orlandi, A. (2011) Application of enhanced stromal vascular fraction and fat grafting mixed with PRP in post-traumatic lower extremity ulcers. Stem Cell Research, 6, 103111. doi:10.1016/j.scr.2010.11.003

[4] Cervelli, V., Scioli, M.G., Gentile, P., Doldo, E., Bonanno, E., Spagnoli, L.G. and Orlandi, A. (2012) Platelet-rich plasma greatly potentiates insulin-induced adipogenic differentiation of human adipose-derived stem cells through a serine/threonine kinase Akt-dependent mechanism and promotes clinical fat graft maintenance. Stem Cells Translational Medicine, 1, 206-220. doi:10.5966/sctm.2011-0052

[5] Gentile, P., Orlandi, A., Scioli, M.G., Di Pasquali, C., Bocchini, I., Curcio, C.B., Floris, M., Fiaschetti, V., Floris, R. and Cervelli, V. (2012) Comparative translational study: The combined use of enhanced stromal vascular fraction and platelet-rich plasma improves fat grafting maintenance in breast reconstruction. Stem Cells Translational Medicine, 1, 341-351. doi:10.5966/sctm.2011-0065

[6] Locke, M., Feisst, V. and Dunbar, P.R. (2011) Concise review: Human adipose-derived stem cells: Separating promise from clinical need. Stem Cells, 29, 404-411. doi:10.1002/stem.593

[7] Manenti, G., Bolacchi, F., Perretta, T., Cossu, E., Pistolese, C.A., Buonomo, O.C., Bonanno, E., Orlandi, A. and Simonetti, G. (2009) Small breast cancers: In vivo percutaneous US-guided radiofrequency ablation with dedicated cool-tip radiofrequency system. Radiology, 251, 339-346. doi:10.1148/radiol.2512080905

[8] Manabe, Y., Toda, S., Miyazaki, K. and Sugihara, H. (2003) Mature adipocytes, but not preadipocytes, promote the growth of breast carcinoma cells in collagen gel matrix culture through cancer stromal cell interactions. The Journal of Pathology, 201, 221-228. doi:10.1002/path.1430

[9] Iyengar, P., Combs, T.P., Shah, S.J., et al. (2003) Adipocyte-secreted factors synergistically promote mammary tumorigenesis through induction of anti-apoptotic transcriptional programs and protooncogene stabilization. Oncogene, 22, 6408-6423. doi:10.1038/sj.onc.1206737

[10] Xu, Q., Wang, L, Li, H., Han, Q., Li, J., Qu, X., Huang, S. and Zhao R.C. (2012) Mesenchymal stem cells play a potential role in regulating the establishment and maintenance of epithelial-mesenchymal transition in MCF7 human breast cancer cells by paracrine and induced autocrine TGF- $\beta$. International Journal of Oncology, 41, 959968. doi:10.3892/ijo.2012.1541

[11] Yu, J.M., Jun, E.S., Bae, Y.C. and Jung, J.S. (2008) Mesenchymal stem cells derived from human adipose tissues favor tumor cell growth in vivo. Stem Cells and Development, 17, 463-473. doi:10.1089/scd.2007.0181

[12] Perrot, P., Rousseau, J., Bouffaut, A.L., Rédini, F., Cassagnau, E., Deschaseaux, F., Heymann, M.F., Heymann, D., Duteille, F., Trichet, V. and Gouin, F. (2010) Safety concern between autologous fat graft, mesenchymal stem cell and osteosarcoma recurrence. PLoS One, 5, Article ID: e10999. doi:10.1371/journal.pone.0010999

[13] Zolochevska, O., Yu, G., Gimble, J.M. and Figueiredo, M.L. (2012) Pigment epithelial-derived factor and melanoma differentiation associated gene-7 cytokine gene therapies delivered by adipose-derived stromal/mesenchymal stem cells are effective in reducing prostate cancer cell growth. Stem Cells, 21, 1112-1123. doi:10.1089/scd.2011.0247

[14] Chandler, E.M., Seo, B.R., Califano, J.P., Andresen Eguiluz, R.C., Lee, J.S., Yoon, C.J., Tims, D.T., Wang, J.X., Cheng, L., Mohanan, S., Buckley, M.R., Cohen, I., Nikitin, A.Y., Williams, R.M., Gourdon, D., ReinhartKing, C.A. and Fischbach, C. (2012) Implanted adipose progenitor cells as physicochemical regulators of breast cancer. Proceedings of the National Academy of Sciences of USA, 109, 9786-9791. doi:10.1073/pnas.1121160109

[15] Orlandi, A., Oliva, F., Taurisano, G., Candi, E., Di Lascio, A., Melino, G., Spagnoli, L.G. and Tarantino, U. (2009) Transglutaminase-2 differently regulates cartilage destruction and osteophyte formation in a surgical model of osteoarthritis. Amino Acids, 36, 755-763. doi:10.1007/s00726-008-0129-3

[16] Cao, L., Shao, M., Schilder, J., Guise, T., Mohammad, K.S. and Matei, D. (2012) Tissue transglutaminase links TGF- $\beta$, epithelial to mesenchymal transition and a stem cell phenotype in ovarian cancer. Oncogene, 31, 25212534. doi:10.1038/onc.2011.429

[17] Pearl, P.R., Leedham, S.J. and Pacifico, M.D. (2012) The safety of autologous fat transfer in breast cancer: Lessons from stem cell biology. Journal of Plastic, Reconstructive \& Aesthetic Surgery, 65, 283-288. doi:10.1016/j.bjps.2011.07.017

[18] Zimmerlin, L., Donnenberg, A.D., Rubin, J.P., Basse, P., Landreneau, R.J. and Donnenberg, V.S. (2011) Regenerative therapy and cancer: In vitro and in vivo studies of the interaction between adipose-derived stem cells and breast cancer cells from clinical isolates. Tissue Engineering Part A, 17, 93-106. doi:10.1089/ten.tea.2010.0248 